\title{
Role of Gut Microbiota-Generated Short-Chain Fatty Acids in Metabolic and Cardiovascular Health
}

\author{
Edward S. Chambers ${ }^{1} \cdot$ Tom Preston $^{2} \cdot$ Gary Frost $^{1} \cdot$ Douglas J. Morrison $^{2}$
}

Published online: 28 September 2018

(C) The Author(s) 2018

\begin{abstract}
Purpose of this Review This review assesses the latest evidence linking short-chain fatty acids (SCFA) with host metabolic health and cardiovascular disease (CVD) risk and presents the latest evidence on possible biological mechanisms.

Recent Findings SCFA have a range of effects locally in the gut and at both splanchnic and peripheral tissues which together appear to induce improved metabolic regulation and have direct and indirect effects on markers of CVD risk.

Summary SCFA produced primarily from the microbial fermentation of dietary fibre appear to be key mediators of the beneficial effects elicited by the gut microbiome. Not only does dietary fibre fermentation regulate microbial activity in the gut, SCFA also directly modulate host health through a range of tissue-specific mechanisms related to gut barrier function, glucose homeostasis, immunomodulation, appetite regulation and obesity. With the increasing burden of obesity worldwide, the role for gut microbiota-generated SCFA in protecting against the effects of energy dense diets offers an intriguing new avenue for regulating metabolic health and CVD risk.
\end{abstract}

Keywords Short-chain fatty acids · Gut microbiome · Fermentation · Glucose homeostasis · Blood pressure · Appetite regulation · Obesity $\cdot$ Inflammation $\cdot$ Metabolic health $\cdot$ Cardiovascular disease

\section{Introduction}

Cardiovascular disease (CVD) is the leading cause of death worldwide, accounting for one in three deaths in the USA [1]. Although significant declines in CVD mortality have been observed in developed countries in the late twentieth century $[2,3]$ owing largely to improvements in public health and healthcare, the burden of CVD still remains high in low and middle-income countries where over three out of four CVD deaths worldwide occur [4]. Diet and lifestyle-related risk factors associated with CVD include smoking, physical inactivity, obesity, diabetes mellitus, dyslipidemia and hypertension.

This article is part of the Topical Collection on Cardiovascular Disease

Douglas J. Morrison

douglas.morrison@glasgow.ac.uk

1 Section for Nutrition Research, Faculty of Medicine, Imperial College London, 6th Floor, Commonwealth Building, Hammersmith Hospital, London, UK

2 Stable Isotope Biochemistry Laboratory, Scottish Universities Environmental Research Centre, University of Glasgow, East Kilbride, Glasgow G75 0QF, Scotland
Recent declines in CVD mortality are however in danger of being reversed with the increased prevalence of obesity. Since the 1980s, the world has seen the prevalence of obesity double and recent worldwide data suggests that there are now more people overweight than underweight globally and in all regions except parts of sub-Saharan Africa and Asia [5]. Looking ahead, in the UK alone, it is forecast that by 2050 , $60 \%$ of males and $50 \%$ of females will be obese [6]. The current and continuing burden of obesity in developed countries and the emerging burden in low and middle-income countries pose a significant challenge to continued decline in CVD mortality.

An emerging area of interest in metabolic health and its link with CVD risk is the gut microbiome. The advent of highthroughput metagenomic techniques has facilitated new insights into the role of the gut microbiome in CVD risk [7]. Importantly, mechanistic insights into the causal pathways are now emerging for microbially mediated production of metabolites that can have both beneficial and detrimental effects on metabolic health and CVD risk [8]. For example, microbially mediated trimethylamine production and subsequent hepatic modification to trimethylamine $\mathrm{N}$-oxide (TMAO) has emerged as a strong microbiome-mediated risk factor for 
CVD [9-11]. Recent faecal microbial transplant work has demonstrated that TMAO production can by modified by targeting the gut microbiome [12•] highlighting the potential of the gut microbiome as a modifiable therapeutic target. The possibilities for modulating gut microbiome activity through dietary, biological or xenobiotic approaches makes this "organ" an attractive target for a range of host health outcomes, with potential for cost-effective individual and population scale interventions. The primary function of the gut microbiome is to process undigested material eluting from the small intestine which includes undigested dietary components and material secreted into the intestine (that remains undigested) by the host including pancreatic secretions, bile acids, mucins and material sloughed from the small intestine through the normal passage of intestinal contents. Of significant biological interest in metabolic health is the role of dietary fibre and the primary products of their breakdown by the gut microbiota, the shortchain fatty acids (SCFA).

\section{Formation and Primary Function of SCFA in Human Health}

A number of recent epidemiological studies have highlighted the inverse association between dietary fibre intake and CVD risk factors [13-18]. Non-digestible carbohydrates (NDC) are an important fraction of dietary fibre and SCFA are the main products of saccharolytic fermentation of NDC in the large intestine. Acetate, propionate and butyrate are the primary SCFA products and are produced in the approximate molar ratio of 60:20:20 reaching a combined concentration of over $100 \mathrm{mM}$ in the intestinal lumen, although circulating concentrations are much lower for propionate and butyrate especially [19]. The balance between saccharolytic fermentation and proteolytic fermentation is primarily related to dietary intake and NDC availability to the microbiota. In elegant work, diet switching experiments have demonstrated rapid changes in microbial metabolic activity and diversity related to the protein, lipid and NDC (dietary fibre) content of the diet [20••, 21]. Thus, the microbiome has become an attractive target because of the ease of its modulation by diet, with the aim of altering host response. SCFA play an important role in host health beyond the recovery of energy from undigested food. Butyrate plays an important role in orchestrating the integrity of the large bowel and small intestinal barrier and supplying energy to epithelial cells in the large intestine [22]. Recent work has also demonstrated a role for butyrate in regulating immune response through expansion of Treg cell populations $[23,24]$ adding to a body of earlier work on the role of SCFA in ameliorating the pro-inflammatory response of immune cells to antigen stimulus (reviewed in [25]). Propionate largely passes across the gut lumen, although a recent study suggests a role for propionate in intestinal gluconeogenesis [26], where it is almost quantitatively sequestrated in the liver where it may act as a gluconeogenic substrate or be oxidised [27]. Some acetate is converted to butyrate by lumenal bacteria; however, acetate largely escapes splanchnic extraction and is available to peripheral tissues where it can be used for lipogenesis in adipose tissue or oxidised by muscle [28]. The role of SCFA, including the tissue-specific metabolism of SCFA, has recently been reviewed elsewhere [29]. The complex luminal, splanchnic and peripheral cell-specific nature of SCFA action and sequestration is illustrated in Fig. 1.

\section{Role of SCFA in Metabolic and Cardiovascular Health}

SCFA have a number of potential roles in modulating metabolic health and CVD risk factors through direct and indirect routes.

Blood Pressure Regulation Possibly the most direct route of modulating CVD risk is SCFA modulation of systolic blood pressure (SBP) and diastolic blood pressure (DBP). A recent controlled trial in humans has demonstrated a potential adjuvant effect of butyrate in the reduction of DPB through a reduction in inflammation [30], and the abundance of butyrate-producing bacteria has been inversely associated with blood pressure and with plasminogen activator inhibitor-1 levels in early pregnancy [31]. Indirect evidence from dietary fibre studies, that should be treated with caution as to the causal role of SCFA because of the pleiotropic effects of dietary fibre, demonstrate that dietary fibre is associated with reduction in BP in Type 1 diabetes (albeit at higher levels of fibre consumption) [32]. A recent meta-analysis concluded that all dietary fibre types when considered together reduced BP ( -0.9 and $-0.7 \mathrm{mmHg}$ for SBP and DBP, respectively) although the effect size was greater for beta-glucan $(-2.9$ and $-1.5 \mathrm{mmHg}$ for SDP and DBP, respectively)-type fibres [33]. The mechanism by which dietary fibres elicit these effects remain to be fully elucidated.

Metabolic Regulation An area where the role of SCFA is gaining much interest is their effects in obesity and metabolic regulation (glucose and lipid homeostasis). Epidemiological and robust animal data demonstrates an inverse relationship between dietary fibre intake and adiposity and weight gain. Recent studies are beginning to provide insight into the role of SCFA. Acetate plays a role in central appetite regulation [34], and increasing production in the distal colon may be more effective than the proximal colon, promoting fat oxidation, improved glucose homeostasis and inflammatory status [35•]. The role of acetate in energy homeostasis and substrate metabolism has recently been reviewed elsewhere [36]. Our recent work using an inulin propionate ester to target deliver to the large intestine has demonstrated in controlled human trials that propionate directly attenuates appetite and food intake 


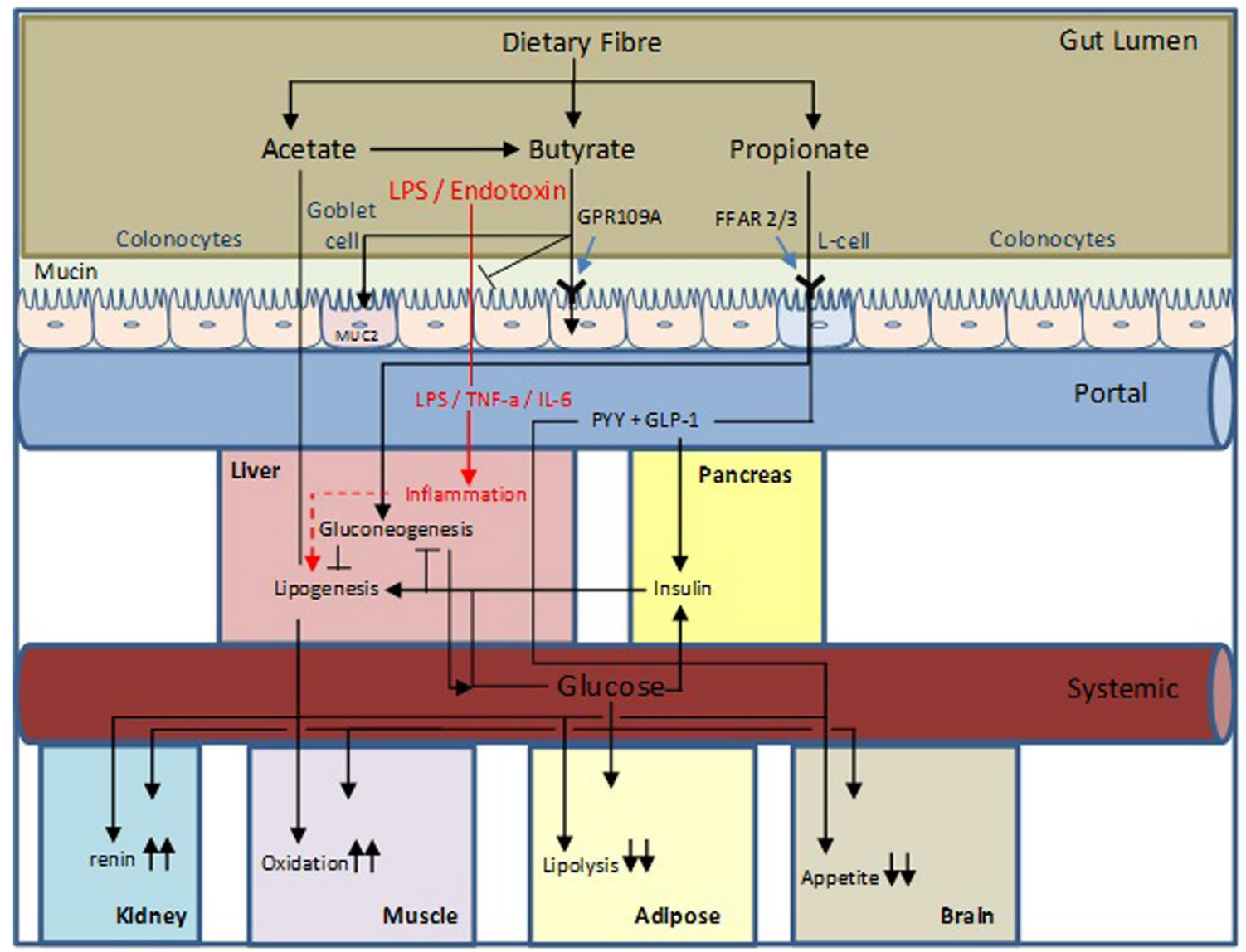

Fig. 1 Overview of the mechanisms of action of SCFA in metabolic health and CVD. Acetate produced in microbial fermentation in the gut largely escapes first-pass metabolism in the liver. It can contribute acetyl units to lipogenesis in the cytosol of hepatocytes and adipocytes but its primary site of oxidation is peripheral muscle. It can also regulate adipose tissue lipolysis and can act on central appetite regulation. Propionate acts locally in the gut on enteroendocrine L-cells to stimulate release of the anorexigenic gut hormones PYY and GLP-1. Propionate is largely absorbed across the intestine and sequestrated primarily in the liver where it can be oxidised or used in gluconeogenesis. Butyrate is largely oxidised at the gut epithelium where it plays a central role in orchestrating the tight junction protein complexes to control gut barrier function. It also plays role in regulating inflammatory cell populations and function through receptor-mediated and histone deacetylation mechanisms. All three SCFA potentially play a role in blood pressure regulation; acetate and propionate through a complex interplay involving renin production mediated through Olfr78 and counter-regulation through FFAR3 and butyrate through attenuation of angiotensin II-induced expression of renal prorenin receptors and renin

Gut Barrier Function Perhaps the most intriguing role for SCFA that may have the greatest impact on host metabolic health is their importance in orchestrating the epithelial barrier to maintain gut integrity and prevent the translocation of bacterial pro-inflammatory molecules across the gut wall. Of the SCFA produced in the colon, current evidence points towards a key regulatory role for butyrate. A plethora of animal studies have promoted a key role for butyrate in maintaining epithelial integrity $[52,53]$ and restoring normal barrier function in challenge models of disease [54-57] primarily through orchestration of the tight junction proteins which govern paracellular permeability and solute transport through the channels between intestinal cells [58]. The consequence of maintaining an optimal gut barrier is preventing the translocation of microbial cell wall components, like lipopolysaccharide, which are strongly pro-inflammatory. An additional pivotal role for butyrate is the induction of mucin production 
which creates a physical barrier between luminal bacterial and epithelial cells [59]. Interestingly, in a recent human study examining gut permeability in hypertension, markers of increased gut permeability and LPS were elevated in hypertensive individuals and a strong correlation was observed between gut permeability and SBP [60•]. The study was only able to demonstrate a protective role for butyrate however in an associated mouse model experiment. Inulin, which is rapidly fermented to SCFA, improves intestinal function in mice [61] but improvements in barrier function were not observed in humans [62] which create uncertainty about translation of findings from animals to humans.

Gut Microbial Function Recent evidence from animal studies suggest that soluble dietary fibre reduces TMA and TMAO metabolism by 40.6 and $62.6 \%$, respectively, which was associated with increased SCFA production and reduced serum lipids and cholesterol [63]. In contrast, inulin supplementation in humans had no effect on fasting or post-prandial TMAO levels [64], indicating the challenges in translating findings from animals to humans and the complexity of the role of different dietary fibres on microbial activity.

\section{Mechanistic Insights into The Role of SCFA in Metabolic and Cardiovascular Health}

SCFA Are Ligands for Several Receptors A number of now deorphaned $G$ protein coupled receptors have been identified for which SCFA act as natural ligands $[65,66]$. Free fatty acids receptors (FFAR) 2 and 3, which have higher affinity for acetate and propionate, are expressed in the intestine, adipose tissue, pancreas and a number of immune cell subtypes. GPR109A has higher affinity for butyrate and may play a role in inflammatory pathways in the intestine [67]. Olfactory receptor 78 (Olfr78) receptors have higher affinity for acetate and propionate and are localised in autonomic nerves in the heart and gut, in the smooth muscle cells of arteries and in renal juxtaglomerular cells [68 ${ }^{\bullet}$. SCFA also function as histone deacetylase inhibitors (HDACs). Histone acetylation is a key regulator of transcription factor activation and downstream gene expression through regulation of chromatin structure.

Blood Pressure The role of SCFA in the regulation of blood pressure has been examined, mainly in animal models. Acetate and propionate appear to regulate blood pressure in a complex interplay involving induction of renin production through Olfr78 and counter-regulation through FFAR3. Evidence from knock out models suggests that propionate induces release of renal renin and a rise in BP through Olfr78 but can also induce a reduction in BP that appears FFAR3 dependent $[68 \bullet, 69]$. In rats, butyrate has been shown to lower BP by attenuating angiotensin II-induced expression of renal prorenin receptors and renin [70]. However, given the low circulating concentration of butyrate in humans [71], whether this pathway is physiologically relevant requires further research to elucidate. Circulating concentrations of propionate and butyrate in humans are generally $<10 \mu \mathrm{mol} / \mathrm{L}$ [71] whereas in animal studies concentrations examined vary from physiological $<10 \mu \mathrm{mol} / \mathrm{L}[70]$ to supra-physiological $>0.1-$ $10 \mathrm{mmol} / \mathrm{L}$ concentrations $\left[68^{\bullet}\right]$.

Gut Barrier Function SCFA and butyrate in particular have long been recognised as important substrates for maintaining a healthy gut. Butyrate is the preferred substrate for colonocytes. More recently, a role for SCFA in regulating epithelial integrity through co-ordinated regulation of tight junction proteins which regulate the intracellular molecular highway between the lumen and hepatic portal system has been postulated. Hyperglycaemia and increased gut permeability are associated with translocation of bacteria and/or their cell wall components which trigger an inflammatory cascade that has been associated with obesity and insulin resistance [72•]. In mice, butyrate can also act on nucleotidebinding oligomerization domain-like receptors (NLRs), key modulators of inflammation in an FFAR2 dependent manner to regulate key components of the tight junction complex [73]. Work in cell models has revealed a possible role for $\mathrm{p} 38$ MAPK [74], IL-10 receptor mediated [75] and AMPK/intracellular ATP [76] regulation of claudin proteins by butyrate. Intriguingly, the involvement of FFAR2 in this pathway opens up a role for other SCFA in regulating barrier function also [77]. In a high-fat diet-induced steatohepatitis mouse model, butyrate was observed to attenuate steatohepatitis through improvement in high-fat diet-induced intestinal mucosa damage, upregulation of zonulin and reduced endotoxin levels [78]. These improvements were associated with downregulation of endotoxin-associated genes (TLR4 and Myd88) and expression of pro-inflammatory genes (MCP-1, TNF- $\alpha$, IL-1, IL-2, IL- 6 and IFN- $\gamma$ ) in the liver. Given the emerging critical role of maintaining a competent physical barrier in the gut between the luminal bacteria and the host immune system, well-designed human studies are warranted to elucidate the role of SCFA in gut barrier function.

Appetite Regulation and Energy Intake SCFA have been suggested to protect against diet-induced obesity by reducing appetite and energy intake. However, a number of studies have reported that incorporating SCFA into the diet of rodents has no effect on food intake [26, 79]. Similarly, in humans, directly incorporating propionate into the diet had no effect on energy intake at an ad libitum test meal or over the 24-h period following consumption [80]. Oral SCFA are rapidly absorbed from the upper gastrointestinal tract, thus may not markedly raise concentrations in the gut lumen. This would appear to be important for SCFA to promote an effect on appetite regulation. 
A recent study by $\mathrm{Li}$ et al. reported a reduction in energy intake following intragastric administration of butyrate but not through intravenous administration of butyrate [42]. This disparity in results may be due to the fact that intragastric administration allows butyrate to reach its natural site of production in the gut lumen and therefore interact with intestinal receptors, which is not achieved with peripheral administration. Using a targeted approach to delivering propionate to the large intestine, we have demonstrated that propionate induces appetite regulation, reduced food intake and prevent weight gain in humans [37].

The available rodent and human studies therefore suggest that oral SCFA supplementation does not modulate appetite responses, whilst delivering SCFA to more distally in the gut may reduce energy intake. The SCFA receptors FFAR2 and FFAR3 are co-expressed in glucagon-like peptide 1 (GLP-1) and peptide YY (PYY) expressing cells [65], leading to the suggestion that SCFAs might reduce energy intake via stimulating the release of these anorectic hormones. Several studies using in vitro models of enteroendocrine cell lines have investigated this effect of SCFAs on gut hormone release [81]. These reports highlight that SCFAs can stimulate anorectic gut hormone release via FFAR2. It has also been suggested that high levels of SCFA in the lower gut could modulate energy intake via gut-brain neural circuits. For example, De Vadder et al. reported that elevated colonic propionate production could induce vagal signalling in the gut or portal vein via FFAR3 [26]. Similarly, Li et al. found that the decrease in food intake following intragastric administration of butyrate in mice was blocked after vagotomy [42].

In summary, studies that have targeted delivery of SCFA to the GI tract have shown reductions in energy intake, which may be related to the anorectic gut hormone release and/or direct neural gut-brain signalling via FFAR2 and FFAR3 receptors. SCFA may also modulate body weight and obesity by increasing energy expenditure. Indeed, a number of studies have reported that both acute and chronic administration of SCFAs promotes energy expenditure in rodents [42, 82, 83]. Available studies in humans have also shown that colonic [43] and oral SCFA [41] supplementation raises rates of energy expenditure. It has consistently been reported that the increase in energy expenditure stimulated by SCFA is associated with a promotion in whole-body lipid oxidation $[41,43,79]$. The increase in energy expenditure and lipid oxidation by SCFA administration has been postulated to be due to stimulation of sympathetic nervous system (SNS) activity, via FFAR3 expressed at the level of the sympathetic ganglion [84], an increase in brown adipose tissue (BAT) activity [42] and via suppression of PPAR $\gamma$ in peripheral tissues, which upregulates lipid oxidation [79].

Glucose Homeostasis SCFA have important effects on glucose homeostasis through a range of mechanisms. As previously described, improved gut barrier function reduces inflammation and oxidative stress promoting improved insulin sensitivity (reviewed in [85]). In dietary fibre supplementation studies in humans, increased plasma propionate has been associated with a reduction in post-prandial insulin [86] and improved glucose homeostasis [37] through improved pancreatic $\beta$-cell function [39] although supplementation with resistant starch observed improvements in glucose homeostasis that appeared to be independent of circulating SCFA and were explained by decreased free fatty acid output [87]. Acetate and butyrate may also play a role in maintaining $\beta$-cell function through their action on cytotoxic $\mathrm{T}$ cells, mediated via B-cells and direct action of SCFA on regulatory T cell populations [88 ${ }^{\bullet}$.

Obesity SCFA protect against diet-induced obesity through a number of mechanisms. SCFA produced in the colon stimulate FFAR $2 / 3$ on enteroendocrine L-cells in the colon leading to release of the anorexigenic gut hormones GLP-1 and PYY $[81,89]$. The role of acetate in appetite regulation, adiposity and weight gain is controversial. Frost et al. demonstrated that acetate induced central appetite regulation and reduced food intake in mice protecting against diet-induced weight gain [34]. More recently, Perry et al. have demonstrated that acetate has the opposite effect, leading to increased glucosestimulated insulin secretion, increased ghrelin secretion, hyperphagia and obesity in mice [90]. These conflicting results require further work to decipher but may be associated with metabolic status and site of acetate administration [36].

Using a targeted approach to delivering propionate to the large intestine, we have demonstrated that propionate induces appetite regulation, reduced food intake and prevent weight gain in humans that may in part be explained by increased GLP-1 and PYY [37]. In mice, SCFA have been shown to decrease PPAR $\gamma$ expression and activity leading to increased expression of mitochondrial uncoupling protein 2 and increased AMP-to-ATP ratio, stimulating oxidative metabolism in the liver and adipose tissue via AMPK [79]. Butyrate may also play a role in preventing diet-induced obesity through increasing energy expenditure by activating of $\beta 3$ adrenergic receptor mediated lipolysis in white adipose tissue [82] and through activation of the adiponectin-mediated pathway and stimulation of mitochondrial function in the skeletal muscle [91]. In a type 2 diabetes mouse model, butyrate - a potent HDAC inhibitor-attenuated myocyte apoptosis, reduced production of reactive oxygen species and increased angiogenesis through MKK3/p38/PRAK activation [92]. Accumulation of fat in the liver is associated with impaired hepatic insulin sensitivity and is associated with type 2 diabetes [93]. In humans [40] and mice [94], propionate has been associated with preventing hepatic lipid accumulation through suppression of genes involved in fatty acid synthesis and potentially through competition for intracellular co-enzyme A stores. 


\section{Conclusions and Future Perspectives}

There is quite compelling evidence from animal models that SCFA can play an important role in regulating metabolic health and mitigating CVD risk. However, careful interpretation of the evidence is necessary particularly when using global genetic knockout models because of the tissue-specific nature of expression of receptors for SCFA. Furthermore, cognisance must be made of the physiologically relevant concentrations that various tissues are exposed to. Whilst oral supplementation or gavage with SCFA is practical and attractive for animal studies, this is generally not how SCFA appear in the gut in humans. The site and rate of SCFA production in the gut may be critical to the physiological consequences and therefore modelling human physiology is important to correctly interpreting animal studies. Better still, well-controlled human intervention studies are needed to develop a strong evidence base if the research and clinical community are to be convinced of the beneficial role SCFA play in human health. With emerging effects around the importance of SCFA for the regulation of barrier function and inflammation, it is critical that we understand the relevance of these effects for disease mitigation because there are relatively inexpensive options to intervene at the population level. The role of SCFA in managing adiposity and body weight gain is well documented in animals and the emergent role of SCFA in appetite regulation and obesity in humans also presents an exciting opportunity to intervene at a population level to tackle perhaps the most pressing health issue of our time - obesity.

Acknowledgements This article was enabled by support from the UK Biotechnology and Biological Sciences Research Council (BB/ L004259/1, BB/H004815/1) and was supported by the NIHR CRF $\mathrm{BRC}$ at Imperial College (IC) Healthcare NHS Trust. The views expressed are those of the authors and not necessarily those of IC, the NHS, the NIHR or the Department of Health. The Division of Diabetes, Endocrinology and Metabolism and Investigative Medicine is funded by grants from the MRC, BBSRC, NIHR, an Integrative Mammalian Biology (IMB) Capacity Building Award, an FP7- HEALTH- 2009241592 EuroCHIP grant and is supported by the NIHR Biomedical Research Centre Funding Scheme. GF holds an NIHR Senior Investigator Award.

\section{Compliance with Ethical Standards}

Conflict of Interest Edward S. Chambers declares that he has no conflict of interest.

Tom Preston is a co-inventor on issued patent \#WO2014020344 ("Compounds and their effects on appetite control and insulin sensitivity"). Gary Frost is a co-inventor on issued patent \#WO2014020344 ("Compounds and their effects on appetite control and insulin sensitivity").

Douglas J. Morrison is a co-inventor on issued patent \#WO2014020344 ("Compounds and their effects on appetite control and insulin sensitivity").

Human and Animal Rights and Informed Consent This article does not contain any studies with human or animal subjects performed by any of the authors.
Open Access This article is distributed under the terms of the Creative Commons Attribution 4.0 International License (http:// creativecommons.org/licenses/by/4.0/), which permits unrestricted use, distribution, and reproduction in any medium, provided you give appropriate credit to the original author(s) and the source, provide a link to the Creative Commons license, and indicate if changes were made.

\section{References}

Papers of particular interest, published recently, have been highlighted as:

- Of importance

•- Of major importance

1. Mozaffarian D, Benjamin EJ, Go AS, Arnett DK, Blaha MJ, Cushman M, et al. Heart Disease and Stroke Statistics-2016 update: a report from the American Heart Association. Circulation. 2016;133(4):e38-360. https://doi.org/10.1161/CIR. 0000000000000350 .

2. Roth GA, Johnson CO, Abate KH, Abd-Allah F, Ahmed M, Alam $\mathrm{K}$, et al. The burden of cardiovascular diseases among US states, 1990-2016. JAMA Cardiol. 2018;3(5):375-89. https://doi.org/10. 1001/jamacardio.2018.0385.

3. Bhatnagar P, Wickramasinghe K, Wilkins E, Townsend N. Trends in the epidemiology of cardiovascular disease in the UK. Heart. 2016;102(24):1945-52. https://doi.org/10.1136/heartjnl-2016-309573.

4. WHO | Global atlas on cardiovascular disease prevention and control. WHO. 2015. doi:/entity/cardiovascular_diseases/publications/ atlas_cvd/en/index.html.

5. Trends in adult body-mass index in 200 countries from 1975 to 2014: a pooled analysis of 1698 population-based measurement studies with 19.2 million participants. Lancet. 2016;387(10026): 1377-96. doi:https://doi.org/10.1016/s0140-6736(16)30054-x.

6. Butland B, Jebb S, Kopelman P, McPherson K, Thomas S, Mardell J. Foresight: Tackling Obesities: Future Choices. http://www. foresight.gov.uk. 2009.

7. Kelly TN, Bazzano LA, Ajami NJ, He H, Zhao J, Petrosino JF, et al. Gut microbiome associates with lifetime cardiovascular disease risk profile among Bogalusa Heart Study participants. Circ Res. 2016;119(8):956-64. https://doi.org/10.1161/circresaha.116.309219.

8. Wang Z, Zhao Y. Gut microbiota derived metabolites in cardiovascular health and disease. Protein Cell. 2018;9:416-31. https://doi. org/10.1007/s13238-018-0549-0.

9. Heianza Y, Ma W, Manson JE, Rexrode KM, Qi L. Gut microbiota metabolites and risk of major adverse cardiovascular disease events and death: a systematic review and meta-analysis of prospective studies. J Am Heart Assoc. 2017;6(7). https://doi.org/10.1161/ jaha.116.004947.

10. Senthong V, Wang Z, Li XS, Fan Y, Wu Y, Tang WH et al. Intestinal microbiota-generated metabolite trimethylamine-N-oxide and 5-year mortality risk in stable coronary artery disease: the contributory role of intestinal microbiota in a COURAGE-like patient cohort. J Am Heart Assoc. 2016;5(6). https://doi.org/10.1161/jaha.115.002816.

11. Zhu W, Wang Z, Tang WHW, Hazen SL. Gut microbe-generated trimethylamine $\mathrm{N}$-oxide from dietary choline is prothrombotic in subjects. Circulation. vol 17. United States2017. p. 1671-1673.

12. Gregory JC, Buffa JA, Org E, Wang Z, Levison BS, Zhu W, et al. Transmission of atherosclerosis susceptibility with gut microbial transplantation. J Biol Chem. 2015;290(9):5647-60. https://doi. org/10.1074/jbc.M114.618249 The study by Gregory et al (2015) demonstrates that a gut microbiome which produces 
higher levels of TMAO can be transplanted to replicate atherosclerotic lesions in an antibiotic-treated apolipoprotein e null mouse model.

13. Hartley L, May MD, Loveman E, Colquitt JL, Rees K. Dietary fibre for the primary prevention of cardiovascular disease. Cochrane Database Syst Rev. 2016(1):Cd011472. https://doi.org/10.1002/ 14651858.CD011472.pub2.

14. Kim Y, Je Y. Dietary fibre intake and mortality from cardiovascular disease and all cancers: a meta-analysis of prospective cohort studies. Arch Cardiovasc Dis. 2016;109(1):39-54. https://doi.org/10. 1016/j.acvd.2015.09.005.

15. Liu L, Wang S, Liu J. Fiber consumption and all-cause, cardiovascular, and cancer mortalities: a systematic review and meta-analysis of cohort studies. Mol Nutr Food Res. 2015;59(1):139-46. https:// doi.org/10.1002/mnfr.201400449.

16. Hajishafiee M, Saneei P, Benisi-Kohansal S, Esmaillzadeh A. Cereal fibre intake and risk of mortality from all causes, CVD, cancer and inflammatory diseases: a systematic review and metaanalysis of prospective cohort studies. Br J Nutr. 2016;116(2):34352. https://doi.org/10.1017/s0007114516001938.

17. Micha R, Shulkin ML, Penalvo JL, Khatibzadeh S, Singh GM, Rao $\mathrm{M}$, et al. Etiologic effects and optimal intakes of foods and nutrients for risk of cardiovascular diseases and diabetes: systematic reviews and meta-analyses from the Nutrition and Chronic Diseases Expert Group (NutriCoDE). PLoS One. 2017;12(4):e0175149. https://doi. org/10.1371/journal.pone.0175149.

18. McRae MP. Dietary fiber is beneficial for the prevention of cardiovascular disease: an umbrella review of meta-analyses. J Chiropr Med. 2017;16(4):289-99. https://doi.org/10.1016/j.jcm.2017.05.005.

19. Boets E, Gomand SV, Deroover L, Preston T, Vermeulen K, De Preter $\mathrm{V}$, et al. Systemic availability and metabolism of colonic-derived shortchain fatty acids in healthy subjects: a stable isotope study. J Physiol. 2017;595(2):541-55. https://doi.org/10.1113/jp272613.

20.• David LA, Maurice CF, Carmody RN, Gootenberg DB, Button JE, Wolfe BE, et al. Diet rapidly and reproducibly alters the human gut microbiome. Nature. 2014;505(7484):559-63. https://doi.org/10. 1038/nature12820 The study by David et al (2014) elegantly demonstrates the rapid change in microbial fermentation patterns and bacterial diversity that are largely driven by dietary inputs reflecting the balance between carbohydrate and protein fermentation by the gut microbiota.

21. O'Keefe SJ, Li JV, Lahti L, Ou J, Carbonero F, Mohammed K, et al. Fat, fibre and cancer risk in African Americans and rural Africans. Nat Commun. 2015;6:6342. https://doi.org/10.1038/ncomms7342.

22. Mathewson ND, Jenq R, Mathew AV, Koenigsknecht M, Hanash A, Toubai T, et al. Gut microbiome derived metabolites modulate intestinal epithelial cell damage and mitigate graft-versus-host disease. Nat Immunol. 2016;17(5):505-13. https://doi.org/10.1038/ni.3400.

23. Arpaia N, Campbell C, Fan XY, Dikiy S, van der Veeken J, deRoos $\mathrm{P}$, et al. Metabolites produced by commensal bacteria promote peripheral regulatory T-cell generation. Nature. 2013;504(7480):451. https://doi.org/10.1038/nature12726.

24. Furusawa Y, Obata Y, Fukuda S, Endo TA, Nakato G, Takahashi D, et al. Commensal microbe-derived butyrate induces the differentiation of colonic regulatory T cells. Nature. 2013;504(7480):446-50. https://doi.org/10.1038/nature12721.

25. Sun $\mathrm{M}, \mathrm{Wu} \mathrm{W}$, Liu Z, Cong Y. Microbiota metabolite short chain fatty acids, GPCR, and inflammatory bowel diseases. J Gastroenterol. 2017;52(1):1-8. https://doi.org/10.1007/s00535016-1242-9.

26. De Vadder F, Kovatcheva-Datchary P, Goncalves D, Vinera J, Zitoun C, Duchampt A, et al. Microbiota-generated metabolites promote metabolic benefits via gut-brain neural circuits. Cell. 2014;156(1-2):84-96. https://doi.org/10.1016/j.cell.2013.12.016.

27. Wilson KA, Han Y, Zhang M, Hess JP, Chapman KA, Cline GW, et al. Inter-relations between 3-hydroxypropionate and propionate metabolism in rat liver: relevance to disorders of propionyl-CoA metabolism. Am J Physiol Endocrinol Metab. 2017;313(4):E413e28. https://doi.org/10.1152/ajpendo.00105.2017.

28. den Besten G, Lange K, Havinga R, van Dijk TH, Gerding A, van Eunen K, et al. Gut-derived short-chain fatty acids are vividly assimilated into host carbohydrates and lipids. Am J Physiol Gastrointest Liver Physiol. 2013;305(12):G900-10. https://doi. org/10.1152/ajpgi.00265.2013.

29. Morrison DJ, Preston T. Formation of short chain fatty acids by the gut microbiota and their impact on human metabolism. Gut Microbes. 2016;7(3):189-200. https://doi.org/10.1080/19490976. 2015.1134082.

30. Roshanravan N, Mahdavi R, Alizadeh E, Jafarabadi MA, Hedayati $\mathrm{M}$, Ghavami A, et al. Effect of butyrate and inulin supplementation on glycemic status, lipid profile and glucagon-like peptide 1 level in patients with type 2 diabetes: a randomized double-blind. PlaceboControlled Trial Horm Metab Res. 2017;49(11):886-91. https://doi. org/10.1055/s-0043-119089.

31. Gomez-Arango LF, Barrett HL, McIntyre HD, Callaway LK, Morrison M, Dekker NM. Increased systolic and diastolic blood pressure is associated with altered gut microbiota composition and butyrate production in early pregnancy. Hypertension. 2016;68(4): 974-81. https://doi.org/10.1161/hypertensionaha.116.07910.

32. Beretta MV, Bernaud FR, Nascimento C, Steemburgo T, Rodrigues TC. Higher fiber intake is associated with lower blood pressure levels in patients with type 1 diabetes. Arch Endocrinol Metab. 2018;62(1):47-54. https://doi.org/10.20945/2359-3997000000008.

33. Evans CE, Greenwood DC, Threapleton DE, Cleghorn CL, Nykjaer C, Woodhead CE, et al. Effects of dietary fibre type on blood pressure: a systematic review and meta-analysis of randomized controlled trials of healthy individuals. J Hypertens. 2015;33(5):897-911. https://doi.org/ 10.1097/hjh.0000000000000515.

34. Frost G, Sleeth ML, Sahuri-Arisoylu M, Lizarbe B, Cerdan S, Brody L, et al. The short-chain fatty acid acetate reduces appetite via a central homeostatic mechanism. Nat Commun. 2014;5:3611. https://doi.org/10.1038/ncomms4611.

35. van der Beek CM, Canfora EE, Lenaerts K, Troost FJ, Olde Damink SWM, Holst JJ, et al. Distal, not proximal, colonic acetate infusions promote fat oxidation and improve metabolic markers in overweight/obese men. Clin Sci (Lond). 2016;130(22):2073-82. https://doi.org/10.1042/cs20160263 The study by van der Beek (2016) highlights the importance of regional SCFA producton in the gut and that studies using oral versus regional delivery of SCFA need to be interpreted with caution due to the regional and tissue-specific nature of SCFA physiology.

36. Canfora EE, Blaak EE. Acetate: a diet-derived key metabolite in energy metabolism: good or bad in context of obesity and glucose homeostasis? Curr Opin Clin Nutr Metab Care. 2017;20(6):47783. https://doi.org/10.1097/mco.0000000000000408.

37. Chambers ES, Viardot A, Psichas A, Morrison DJ, Murphy KG, Zac-Varghese SEK, et al. Effects of targeted delivery of propionate to the human colon on appetite regulation, body weight maintenance and adiposity in overweight adults. Gut. 2014;64:1744-54. https://doi.org/10.1136/gutjnl-2014-307913.

38. Byrne CS, Chambers ES, Alhabeeb H, Chhina N, Morrison DJ, Preston $\mathrm{T}$, et al. Increased colonic propionate reduces anticipatory reward responses in the human striatum to high-energy foods. Am J Clin Nutr. 2016;104(1):5-14. https://doi.org/10.3945/ajen.115.126706.

39. Pingitore A, Chambers ES, Hill T, Maldonado IR, Liu B, Bewick $\mathrm{G}$, et al. The diet-derived short chain fatty acid propionate improves beta-cell function in humans and stimulates insulin secretion from human islets in vitro. Diabetes Obes Metab. 2017;19(2):257-65. https://doi.org/10.1111/dom.12811.

40. Chambers ES, Byrne CS, Rugyendo A, Morrison DJ, Preston T, Tedford MC, et al. The effects of dietary supplementation with inulin and inulin-propionate ester on hepatic steatosis in adults with 
non-alcoholic fatty liver disease. Diabetes Obes Metab. 2018. https://doi.org/10.1111/dom.13500.

41. Chambers ES, Byrne CS, Aspey K, Chen Y, Khan S, Morrison DJ, et al. Acute oral sodium propionate supplementation raises resting energy expenditure and lipid oxidation in fasted humans. Diabetes Obes Metab. 2018;20(4):1034-9. https://doi.org/10.1111/dom. 13159.

42. Li Z, Yi CX, Katiraei S, Kooijman S, Zhou E, Chung CK, et al. Butyrate reduces appetite and activates brown adipose tissue via the gut-brain neural circuit. Gut. 2018;67(7):1269-79. https://doi.org/ 10.1136/gutjnl-2017-314050.

43. Canfora EE, van der Beek CM, Jocken JWE, Goossens GH, Holst JJ, Olde Damink SWM, et al. Colonic infusions of short-chain fatty acid mixtures promote energy metabolism in overweight/obese men: a randomized crossover trial. Sci Rep. 2017;7(1):2360. https://doi.org/10.1038/s41598-017-02546-x.

44. Nicolucci AC, Hume MP, Martinez I, Mayengbam S, Walter J, Reimer RA. Prebiotics reduce body fat and Alter intestinal microbiota in children who are overweight or with obesity. Gastroenterology. 2017;153(3):711-22. https://doi.org/10.1053/j. gastro.2017.05.055.

45. van der Beek CM, Canfora EE, Kip AM, Gorissen SHM, Olde Damink SWM, van Eijk HM, et al. The prebiotic inulin improves substrate metabolism and promotes short-chain fatty acid production in overweight to obese men. Metabolism. 2018;87:25-35. https://doi.org/10.1016/j.metabol.2018.06.009.

46. Weitkunat K, Stuhlmann C, Postel A, Rumberger S, Fankhanel M, Woting A, et al. Short-chain fatty acids and inulin, but not guar gum, prevent diet-induced obesity and insulin resistance through differential mechanisms in mice. Sci Rep. 2017;7(1):6109. https:// doi.org/10.1038/s41598-017-06447-x.

47. Singh A, Zapata RC, Pezeshki A, Reidelberger RD, Chelikani PK. Inulin fiber dose-dependently modulates energy balance, glucose tolerance, gut microbiota, hormones and diet preference in highfat-fed male rats. J Nutr Biochem. 2018;59:142-52. https://doi. org/10.1016/j.jnutbio.2018.05.017.

48. Reimer RA, Willis HJ, Tunnicliffe JM, Park H, Madsen KL, SotoVaca A. Inulin-type fructans and whey protein both modulate appetite but only fructans alter gut microbiota in adults with overweight/obesity: a randomized controlled trial. Mol Nutr Food Res. 2017;61(11). https://doi.org/10.1002/mnfr.201700484.

49. Hume MP, Nicolucci AC, Reimer RA. Prebiotic supplementation improves appetite control in children with overweight and obesity: a randomized controlled trial. Am J Clin Nutr. 2017;105(4):790-9. https://doi.org/10.3945/ajcn.116.140947.

50. Guess ND, Dornhorst A, Oliver N, Frost GS. A randomised crossover trial: the effect of inulin on glucose homeostasis in subtypes of prediabetes. Ann Nutr Metab. 2016;68(1):26-34. https://doi.org/10. $1159 / 000441626$.

51. Liu F, Prabhakar M, Ju J, Long H, Zhou HW. Effect of inulin-type fructans on blood lipid profile and glucose level: a systematic review and meta-analysis of randomized controlled trials. Eur J Clin Nutr. 2017;71(1):9-20. https://doi.org/10.1038/ejen.2016.156.

52. Gonzalez A, Krieg R, Massey HD, Carl D, Ghosh S, Gehr TWB, et al. Sodium butyrate ameliorates insulin resistance and renal failure in CKD rats by modulating intestinal permeability and mucin expression. Nephrol Dial Transplant. 2018. https://doi.org/10.1093/ ndt/gfy238.

53. Feng W, Wu Y, Chen G, Fu S, Li B, Huang B, et al. Sodium butyrate attenuates diarrhea in weaned piglets and promotes tight junction protein expression in colon in a GPR109A-dependent manner. Cell Physiol Biochem. 2018;47(4):1617-29. https://oi. org/10.1159/000490981.

54. Hu ED, Chen DZ, Wu JL, Lu FB, Chen L, Zheng MH, et al. High fiber dietary and sodium butyrate attenuate experimental autoimmune hepatitis through regulation of immune regulatory cells and intestinal barrier. Cell Immunol. 2018;328:24-32. https://doi.org/ 10.1016/j.cellimm.2018.03.003.

55. Matheus VA, Monteiro L, Oliveira RB, Maschio DA, CollaresBuzato CB. Butyrate reduces high-fat diet-induced metabolic alterations, hepatic steatosis and pancreatic beta cell and intestinal barrier dysfunctions in prediabetic mice. Exp Biol Med (Maywood). 2017:1535370217708188. https://doi.org/10.1177/ 1535370217708188.

56. Han X, Song H, Wang Y, Sheng Y, Chen J. Sodium butyrate protects the intestinal barrier function in peritonitic mice. Int J Clin Exp Med. 2015;8(3):4000-7.

57. Yang F, Wang LK, Li X, Wang LW, Han XQ, Gong ZJ. Sodium butyrate protects against toxin-induced acute liver failure in rats. Hepatobiliary Pancreat Dis Int. 2014;13(3):309-15.

58. Morkl S, Lackner S, Meinitzer A, Mangge H, Lehofer M, Halwachs $\mathrm{B}$, et al. Gut microbiota, dietary intakes and intestinal permeability reflected by serum zonulin in women. Eur J Nutr. 2018. https://doi. org/10.1007/s00394-018-1784-0.

59. Cornick S, Tawiah A, Chadee K. Roles and regulation of the mucus barrier in the gut. Tissue Barriers. 2015;3(1-2):e982426. https://doi. org/10.4161/21688370.2014.982426.

60. Kim S, Goel R, Kumar A, Qi Y, Lobaton G, Hosaka K, et al. Imbalance of gut microbiome and intestinal epithelial barrier dysfunction in patients with high blood pressure. Clin Sci (Lond). 2018;132(6):701-18. https://doi.org/10.1042/cs20180087 The study by Kim et al (2018) is noteworthy because of the observed association between a range of markers for gut barrier function and blood pressure. Although a causal relationship has not been established in humans, animal model data suggests a key role for the SCFA butyrate.

61. Liu TW, Cephas KD, Holscher HD, Kerr KR, Mangian HF, Tappenden KA, et al. Nondigestible fructans alter gastrointestinal barrier function, gene expression, histomorphology, and the microbiota profiles of diet-induced obese C57BL/6J mice. J Nutr. 2016;146(5):949-56. https://doi.org/10.3945/jn.115.227504.

62. Ferolla SM, Couto CA, Costa-Silva L, Armiliato GN, Pereira CA, Martins FS et al. Beneficial effect of synbiotic supplementation on hepatic steatosis and anthropometric parameters, but not on gut permeability in a population with nonalcoholic steatohepatitis. Nutrients. 2016;8(7). https://doi.org/10.3390/nu8070397.

63. Li Q, Wu T, Liu R, Zhang M, Wang R. Soluble Dietary fiber reduces trimethylamine metabolism via gut microbiota and coregulates host AMPK pathways. Mol Nutr Food Res. 2017;61(12). https://doi.org/10.1002/mnfr.201700473.

64. Baugh ME, Steele CN, Angiletta CJ, Mitchell CM, Neilson AP, Davy BM et al. Inulin Supplementation does not reduce plasma trimethylamine $\mathrm{N}$-oxide concentrations in individuals at risk for type 2 diabetes. nutrients. 2018;10(6). https://doi.org/10.3390/ nu10060793.

65. Kimura I, Inoue D, Hirano K, Tsujimoto G. The SCFA receptor GPR43 and energy metabolism. Front Endocrinol (Lausanne). 2014;5:85. https://doi.org/10.3389/fendo.2014.00085.

66. Bolognini D, Tobin AB, Milligan G, Moss CE. The pharmacology and function of receptors for short-chain fatty acids. Mol Pharmacol. 2016;89(3):388-98. https://doi.org/10.1124/mol.115. 102301.

67. Singh N, Gurav A, Sivaprakasam S, Brady E, Padia R, Shi H, et al. Activation of the receptor (Gpr109a) for niacin and the commensal metabolite butyrate suppresses colonic inflammation and carcinogenesis. Immunity. 2014;40(1):128-39. https://doi.org/10.1016/j. immuni.2013.12.007.

68. Pluznick JL, Protzko RJ, Gevorgyan H, Peterlin Z, Sipos A, Han J, et al. Olfactory receptor responding to gut microbiota-derived signals plays a role in renin secretion and blood pressure regulation. Proc Natl Acad Sci U S A. 2013;110(11):4410-5. https://doi.org/ 10.1073/pnas.1215927110 The study by Pluznick et al (2013) 
demonstrated the complex biological regulation of blood pressure through the counter-acting role of SCFA on the receptors Olfr78 and FFAR 3 expressed in renal juxtaglomerular cells and smooth muscle cells in blood vessels.

69. Natarajan N, Hori D, Flavahan S, Steppan J, Flavahan NA, Berkowitz DE, et al. Microbial short chain fatty acid metabolites lower blood pressure via endothelial $\mathrm{G}$ protein-coupled receptor 41. Physiol Genomics. 2016;48(11):826-34. https://doi.org/10.1152/ physiolgenomics.00089.2016.

70. Wang L, Zhu Q, Lu A, Liu X, Zhang L, Xu C, et al. Sodium butyrate suppresses angiotensin II-induced hypertension by inhibition of renal (pro)renin receptor and intrarenal renin-angiotensin system. J Hypertens. 2017;35(9):1899-908. https://doi.org/10. 1097/hjh.0000000000001378.

71. Boets E, Deroover L, Houben E, Vermeulen K, Gomand SV, Delcour JA, et al. Quantification of in vivo colonic short chain fatty acid production from inulin. Nutrients. 2015;7(11):8916-29. https://doi.org/10.3390/nu7115440.

72. Thaiss CA, Levy M, Grosheva I, Zheng D, Soffer E, Blacher E, et al. Hyperglycemia drives intestinal barrier dysfunction and risk for enteric infection. Science. 2018;359(6382):1376-83. https:// doi.org/10.1126/science.aar3318 The study by Thaiss et al (2018) demonstrates the complex system and reciprocol relationships between gut microbial acitivty, SCFA and glucose homeostasis which in turn impacts upon gut barrier function.

73. Cheng D, Xu JH, Li JY, Wang SY, Wu TF, Chen QK, et al. Butyrate ameliorated-NLRC3 protects the intestinal barrier in a GPR43dependent manner. Exp Cell Res. 2018;368(1):101-10. https:// doi.org/10.1016/j.yexcr.2018.04.018.

74. Huang XZ, Li ZR, Zhu LB, Huang HY, Hou LL, Lin J. Inhibition of p38 mitogen-activated protein kinase attenuates butyrate-induced intestinal barrier impairment in a Caco-2 cell monolayer model. J Pediatr Gastroenterol Nutr. 2014;59(2):264-9. https://doi.org/10. 1097/mpg.0000000000000369.

75. Zheng L, Kelly CJ, Battista KD, Schaefer R, Lanis JM, Alexeev EE, et al. Microbial-derived butyrate promotes epithelial barrier function through IL-10 receptor-dependent repression of claudin2. J Immunol. 2017;199(8):2976-84. https://doi.org/10.4049/ jimmunol.1700105.

76. Yan H, Ajuwon KM. Butyrate modifies intestinal barrier function in IPEC-J2 cells through a selective upregulation of tight junction proteins and activation of the Akt signaling pathway. PLoS One. 2017;12(6):e0179586. https://doi.org/10.1371/journal.pone. 0179586

77. Tong LC, Wang Y, Wang ZB, Liu WY, Sun S, Li L, et al. Propionate ameliorates dextran sodium sulfate-induced colitis by improving intestinal barrier function and reducing inflammation and oxidative stress. Front Pharmacol. 2016;7:253. https://doi.org/10.3389/fphar. 2016.00253

78. Zhou D, Pan Q, Xin FZ, Zhang RN, He CX, Chen GY, et al. Sodium butyrate attenuates high-fat diet-induced steatohepatitis in mice by improving gut microbiota and gastrointestinal barrier. World J Gastroenterol. 2017;23(1):60-75. https://doi.org/10.3748/ wjg.v23.11.60.

79. den Besten G, Bleeker A, Gerding A, van Eunen K, Havinga R, van Dijk TH, et al. Short-chain fatty acids protect against high-fat dietinduced obesity via a PPARgamma-dependent switch from lipogenesis to fat oxidation. Diabetes. 2015;64(7):2398-408. https:// doi.org/10.2337/db14-1213.

80. Darzi J, Frost GS, Robertson MD. Effects of a novel propionaterich sourdough bread on appetite and food intake. Eur J Clin Nutr. 2012;66(7):789-94. https://doi.org/10.1038/ejen.2012.1.

81. Psichas A, Sleeth ML, Murphy KG, Brooks L, Bewick GA, Hanyaloglu AC, et al. The short chain fatty acid propionate stimulates GLP-1 and PYY secretion via free fatty acid receptor 2 in rodents. Int J Obes. 2015;39(3):424-9. https://doi.org/10.1038/ijo. 2014.153.

82. Jia Y, Hong J, Li H, Hu Y, Jia L, Cai D, et al. Butyrate stimulates adipose lipolysis and mitochondrial oxidative phosphorylation through histone hyperacetylation-associated beta3 -adrenergic receptor activation in high-fat diet-induced obese mice. Exp Physiol. 2017;102(2):273-81. https://doi.org/10.1113/ep086114.

83. Henagan TM, Stefanska B, Fang Z, Navard AM, Ye J, Lenard NR, et al. Sodium butyrate epigenetically modulates high-fat diet-induced skeletal muscle mitochondrial adaptation, obesity and insulin resistance through nucleosome positioning. Br J Pharmacol. 2015;172(11):2782-98. https://doi.org/10.1111/bph.13058.

84. Kimura I, Ozawa K, Inoue D, Imamura T, Kimura K, Maeda T, et al. The gut microbiota suppresses insulin-mediated fat accumulation via the short-chain fatty acid receptor GPR43. Nat Commun. 2013;4:1829. https://doi.org/10.1038/ncomms2852.

85. Kim YA, Keogh JB, Clifton PM. Probiotics, prebiotics, synbiotics and insulin sensitivity. Nutr Res Rev. 2018;31(1):35-51. https://doi. org/10.1017/s095442241700018x.

86. Vetrani C, Costabile G, Luongo D, Naviglio D, Rivellese AA, Riccardi G, et al. Effects of whole-grain cereal foods on plasma short chain fatty acid concentrations in individuals with the metabolic syndrome. Nutrition. 2016;32(2):217-21. https://doi.org/10. 1016/j.nut.2015.08.006.

87. Rahat-Rozenbloom S, Fernandes J, Cheng J, Gloor GB, Wolever TM. The acute effects of inulin and resistant-starch on postprandial serum short-chain fatty acids and second-meal glycaemic response in lean and overweight humans. Eur J Clin Nutr. 2017;71(2):22733. https://doi.org/10.1038/ejcn.2016.248.

88. Marino E, Richards JL, McLeod KH, Stanley D, Yap YA, Knight J, et al. Gut microbial metabolites limit the frequency of autoimmune $\mathrm{T}$ cells and protect against type 1 diabetes. Nat Immunol. 2017;18(5):552-62. https://doi.org/10.1038/ni.3713 The study by Marino et al (2017) demonstrates the importance of regional modulation of SCFA production in the gut on conditioning immune cell response in a non-obese diabetic mouse strain to protect against diabetes.

89. Tolhurst G, Heffron H, Lam YS, Parker HE, Habib AM, Diakogiannaki E, et al. Short-chain fatty acids stimulate glucagon-like peptide-1 secretion via the G-protein-coupled receptor FFAR2. Diabetes. 2012;61(2):364-71. https://doi.org/10.2337/ db11-1019.

90. Perry RJ, Peng L, Barry NA, Cline GW, Zhang D, Cardone RL, et al. Acetate mediates a microbiome-brain-beta-cell axis to promote metabolic syndrome. Nature. 2016;534(7606):213-7. https:// doi.org/10.1038/nature18309.

91. Hong J, Jia Y, Pan S, Jia L, Li H, Han Z, et al. Butyrate alleviates high-fat diet-induced obesity through activation of adiponectinmediated pathway and stimulation of mitochondrial function in the skeletal muscle of mice. Oncotarget. 2016;7(35):56071-82. https://doi.org/10.18632/oncotarget.11267.

92. Zhang L, Du J, Yano N, Wang H, Zhao YT, Dubielecka PM, et al. Sodium butyrate protects -against high fat diet-induced cardiac dysfunction and metabolic disorders in type II diabetic mice. J Cell Biochem. 2017;118(8):2395-408. https://doi.org/10.1002/jcb. 25902.

93. Tilg H, Moschen AR, Roden M. NAFLD and diabetes mellitus. Nat Rev Gastroenterol Hepatol. 2017;14(1):32-42. https://doi.org/10. 1038/nrgastro.2016.147.

94. Weitkunat K, Schumann S, Nickel D, Kappo KA, Petzke KJ, Kipp AP, et al. Importance of propionate for the repression of hepatic lipogenesis and improvement of insulin sensitivity in high-fat diet-induced obesity. Mol Nutr Food Res. 2016;60(12):2611-21. https://doi.org/10.1002/mnfr.201600305. 